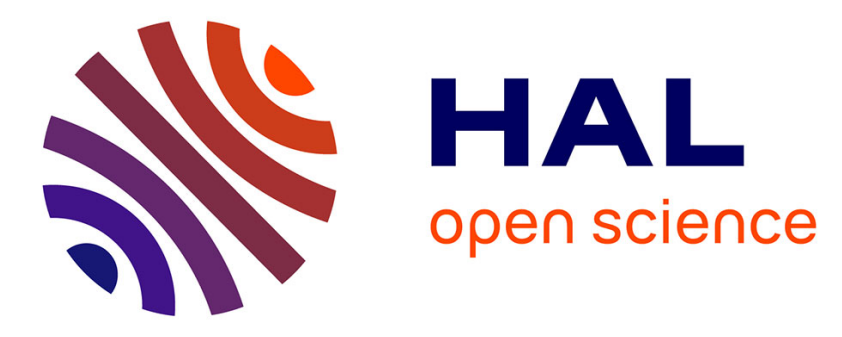

\title{
Deposition of gold nanofeatures on silicon samples by field-induced deposition using a scanning tunneling microscope
}

H. Abed, H. Jamgotchian, H. Dallaporta, B. Gely, P. Bindzi, D. Chatain, S. Nitsche, D. Chaudanson, E. Cambril, V. Safarov, et al.

\section{To cite this version:}

H. Abed, H. Jamgotchian, H. Dallaporta, B. Gely, P. Bindzi, et al.. Deposition of gold nanofeatures on silicon samples by field-induced deposition using a scanning tunneling microscope. Journal of Vacuum Science \& Technology B Microelectronics and Nanometer Structures, 2005, 23 (4), 10.1116/1.1943440 . hal-01722654

\section{HAL Id: hal-01722654 \\ https://hal-amu.archives-ouvertes.fr/hal-01722654}

Submitted on 22 Apr 2020

HAL is a multi-disciplinary open access archive for the deposit and dissemination of scientific research documents, whether they are published or not. The documents may come from teaching and research institutions in France or abroad, or from public or private research centers.
L'archive ouverte pluridisciplinaire HAL, est destinée au dépôt et à la diffusion de documents scientifiques de niveau recherche, publiés ou non, émanant des établissements d'enseignement et de recherche français ou étrangers, des laboratoires publics ou privés.

\section{(c)(1)}

Distributed under a Creative Commons Attribution| 4.0 International License 


\title{
Deposition of gold nanofeatures on silicon samples by field-induced deposition using a scanning tunneling microscope
}

\author{
H. Abed, ${ }^{a)}$ H. Jamgotchian, H. Dallaporta, B. Gely, P. Bindzi, D. Chatain, S. Nitsche, \\ D. Chaudanson, E. Cambril, ${ }^{\text {b) }}$ V. Safarov, and D. Tonneau \\ CRMCN, Faculté des Sciences de Luminy, Case 913, 13288 Marseille cedex 09, France
}

\begin{abstract}
Gold islands of diameter as small as $15 \mathrm{~nm}$ and $6 \mathrm{~nm}$ high were deposited on a standard silicon (100) surface by field-induced deposition using a scanning tunneling microscope operating with $\mathrm{Pt}$ or $\mathrm{W}$ tips coated by a gold film. Gold atoms are transferred by applying to the sample negative voltage pulses of few volts in magnitude, and of some tens of microseconds in duration. The scanning tunneling microscope tip morphology and composition have been analyzed systematically by field-emission gun scanning electron microscope plus energy dispersive x-ray (EDX) microanalysis before and after its use for lithography. The deposits composition have also been analyzed by EDX. Finally, preliminary results on trials of direct bonding of microscopic contact leads are presented.
\end{abstract}

\section{INTRODUCTION}

Generation of nanodots and nanowires is of great interest for the fabrication of single-electron tunneling devices and the bonding of individual nano-objects. In the past few years, many experiments have been performed using a scanning tunneling microscope ${ }^{1-6}$ (STM) or atomic force microscope $^{7-15}$ (AFM) to pattern metallic or silicon nanoscale features. The feasibility of STM lithography by atom transfer from a STM tip to a sample was demonstrated more than 10 years ago. ${ }^{1}$ Some authors suggested that the atom transfer is achieved by tip evaporation enhanced by the high electric field between the tip-sample gap. ${ }^{1,16,17}$ More recently, the deposition has been explained to occur in liquid phase via a field-induced transfer of atoms from the STM tip to the sample. In fact, it seems that the STM tip is elongated under the high tip-sample electric field until a physical tipsample contact is established, ${ }^{3,4}$ which leads to a drastic increase of the tip-sample current. This top-down lithography technique could be particularly suitable for direct bonding of a nano-object, since it is possible with the same tool to image locally the surface by a soft process, to find the object, and to bond it to contact leads and pads predeposited on the sample.

In order to increase the process resolution, the tips must be very sharp. Thus, their apex is prepared by an electrochemical etching step. ${ }^{18,19}$ This requires the optimization of many process parameters among which to choose of the liquid etching solution, the type of bias (dc or ac), amplitude, time. Consequently, to deposit nanofeatures of new metal, it is easier to start from a STM tip of usual metal $(\mathrm{W}, \mathrm{Pt})$ and to coat it with the metal to be deposited. For example, it has been shown that gold patterns could be deposited on a $\operatorname{Si}(111)-(7 \times 7)$ surface from a gold-coated tungsten tip. ${ }^{20}$

This article presents the results of gold nanofeature deposition from platinum and tungsten tips coated by a thin gold

\footnotetext{
${ }^{a)}$ Electronic mail: abed@crmcn.univ-mrs.fr

${ }^{b)}$ LPN-CNRS, Route de Nozay, 91460 Marcoussis, France
}

layer. The deposits composition has been estimated by energy dispersive $\mathrm{x}$-ray microanalysis (EDX), TRACOR SERIE 2, associated with a field-emission gun scanning electron microscope (SEM), JEOL 6320F. The tip morphology has been systematically examined at each step of its preparation process and after lithography. Finally, preliminary results on trials of contact lead connection by this direct technique are presented and discussed.

\section{NANOFABRICATION AND EXPERIMENTAL PROCEDURE}

The experimental setup for direct writing of metallic nanofeatures by field-induced deposition has already been described. ${ }^{4}$ It consists of a STM head ( $\mu$ STM OMICRON) placed in a vacuum chamber operating at a base pressure of

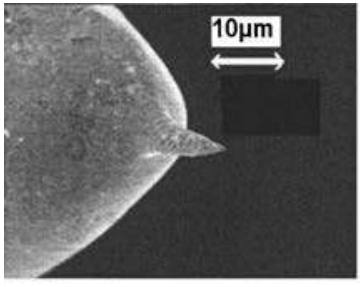

(a)

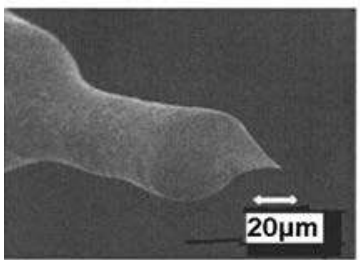

(c)

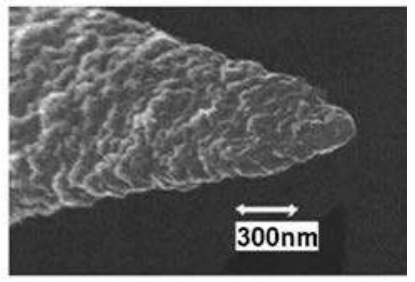

(b)

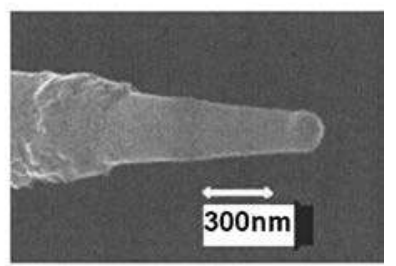

(d)
FIG. 1. SEM analyses at $15 \mathrm{keV}$ of the STM tips (a) Platinum tip fabricated in a $\mathrm{CaCl}_{2}: \mathrm{H}_{2} \mathrm{O}$ :acetone solution under an ac bias fixed in the range of 9-14 V. (b) Zoom on the platinum tip apex. (c) Tungsten tip fabricated in an $\mathrm{NaOH}$ solution, under a de bias fixed in the range of 1-12 V. (d) Zoom on the tungsten tip apex. 

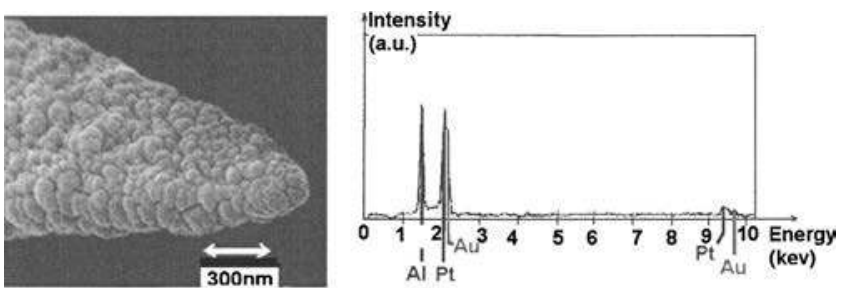

(a)

(b)

FIG. 2. (a) SEM image of the Pt tip shown Fig. 1(a) after Au sputtering. (b) EDX spectrum of the tip (linear scale for a.u.).

$10^{-7}$ mbar achieved with a turbomolecular pump. The scanning window of the STM $X-Y$ piezoelectric ceramics being $5 \times 5 \mu \mathrm{m}^{2}$, the STM is equipped with an optical microscope allowing precise tip positioning on the sample.

Lithography experiments have been carried out on commercial $n$-type $\mathrm{Si}$ (100) with a doping level of 4 $\times 10^{13} \mathrm{~cm}^{-3}$ (resistivity of $100 \Omega \mathrm{cm}$ ) substrate. The samples were first degreased in an inorganic solution of $\mathrm{NH}_{4} \mathrm{OH}$ : $\mathrm{H}_{2} \mathrm{O}_{2}: \mathrm{H}_{2} \mathrm{O}\left(0.5: 0.25: 0.25\right.$ vol.) at $65^{\circ} \mathrm{C}$ during $15 \mathrm{mn}$ and finally etched in a $5 \% \mathrm{HF}$ solution. This treatment leads to a surface passivated by mono-, di-, and trihydride bonds, with predominant content of dihydrides. ${ }^{21}$

Before lithography, the substrate is imaged under a typical sample bias of $V_{\mathrm{im}}=-1.5 \mathrm{~V}$ and a current setpoint of $I_{\mathrm{im}}$ $=500 \mathrm{pA}$, which corresponds to a tip-sample distance of roughly $0.5 \mathrm{~nm} .{ }^{4}$ The tip-to-sample atom transfer occurs when voltage pulses $V_{\text {litho }}$ of amplitude higher than a threshold (typically ranging from -4 to $-7 \mathrm{~V}$ ) is applied to the sample. The value of this threshold depends on the material used for the tip. ${ }^{4}$ Since the gap between the tip and the sample in STM experiments is quite narrow, the feedback loop of the STM must remain activated during nanostructure growth in order to prevent the tip damage due to contact with the deposit while it grows. To avoid tip removal due to the increase of the sample bias, the voltage is applied under a pulse regime with pulse duration lower than the feedback loop constant of the STM (roughly $1 \mathrm{~ms}$ ). The dead time between two successive pulses must be longer than this time constant to allow tip removal after material deposition during one pulse. The typical pulse duration and dead time chosen

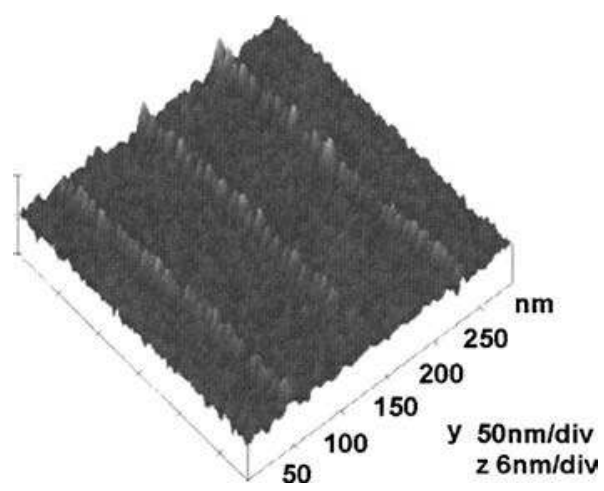

FIG. 3. STM image of gold dotted lines deposited using a Au-coated Pt tip on $\mathrm{Si}(100) n$-type $\left(10^{16} \mathrm{~cm}^{-3}\right)$ substrate. Experimental conditions: $V_{\mathrm{im}}=$ $-1.5 \mathrm{~V}, \quad I_{\text {im }}=500 \mathrm{pA}, t_{\text {pulse }}=50 \mu \mathrm{s}, \quad V_{\text {litho }}=-4.2 \mathrm{~V}, 50$ pulses by dot deposited.

were $100 \mu$ s and $5 \mathrm{~ms}$, respectively. Dotted lines can be drawn by applying identical pulse voltage sequences while the tip scans the surface.

STM tips are prepared by electrochemical etching from a $250 \mu \mathrm{m}$ diameter platinum or tungsten wire. We did not use gold tips due to their low mechanical stability for STM experiments. The polycrystalline Pt tips are formed by a twostep etching in a $\mathrm{CaCl}_{2}: \mathrm{H}_{2} \mathrm{O}$ :acetone $(5.7 \mathrm{mg}$ : $20 \mathrm{ml}: 20$ $\mathrm{ml})^{18,19}$ under an ac bias fixed in the range of 9-14 V. The tip is dipped in the solution to reach an initial current of 120 $\mathrm{mA}$. The current decreases while the tip is etched and the voltage is switched off when the current reaches $90 \mathrm{~mA}$. The tip is rinsed and redipped in the solution for an extra identical step. The first step allows one to preshape the tip, and the final step forms the apex [Fig. 1(a) and zoom on the apex Fig. 1(b)]. The typical curvative radius of such a tip is 50-60 nm.

Tungsten tips are prepared in an etching solution of $\mathrm{NaOH} 3 \mathrm{M},{ }^{18}$ under a dc bias chosen in the range of $1-12 \mathrm{~V}$. In this case, the tungsten wire is deeply dipped in the solution. The etching takes place at the air-liquid interface and a neck is grooved in the wire at this interface. The weight of the wire in the solution induces the creeping and the break-

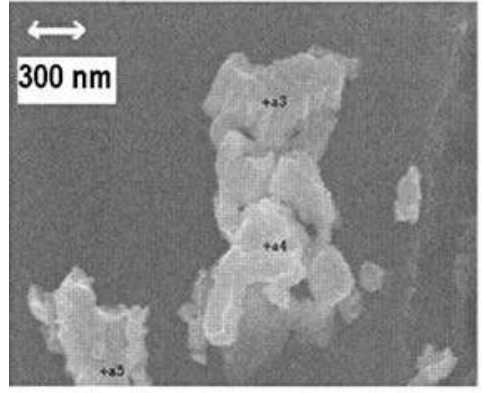

(a)

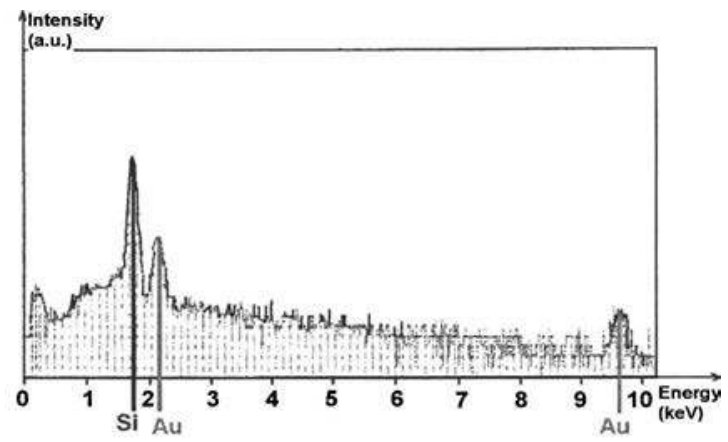

(b)
FIG. 4. (a) SEM image of a dot deposited using a Au-coated Pt tip on $\operatorname{Si}(100) n$-type $\left(10^{16} \mathrm{~cm}^{-3}\right)$ substrate. The experimental conditions were: $V_{\text {im }}=-1.5 \mathrm{~V}, \quad I_{\text {im }}=500 \mathrm{pA}, \quad t_{\text {pulse }}$ $=50 \mu \mathrm{s}, V_{\text {litho }}=-10 \mathrm{~V}$. (b) EDX spectrum of the gold deposit on $\mathrm{Si}$. 


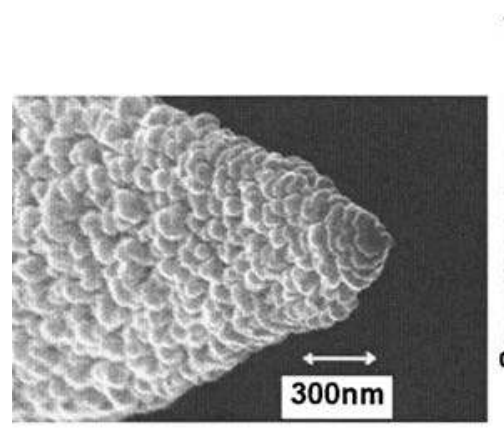

(a)

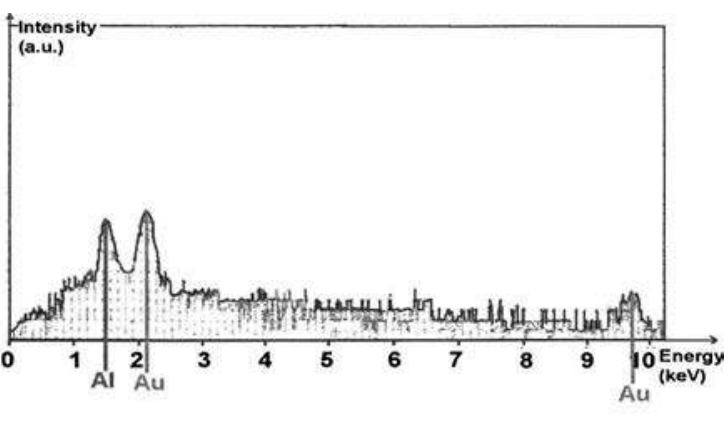

(b)
FIG. 5. Analysis of the tip shown in Fig. 2 after lithography under $V_{\text {litho }}=$ -4.2 V. (a) SEM image. (b) EDX signature (a.u. in logarithmic scale). ing of the wire, leaving the sacrificial part of the tungsten wire in the solution. The typical curvature of such tips is 50 $\mathrm{nm}$ [see SEM analyses, Figs. 1(c) and 1(d)].

\section{RESULTS AND DISCUSSION}

\section{A. Deposition from gold-coated platinum tips}

The platinum tips were coated by a gold layer deposited by plasma deposition in a sputter chamber. The average thickness of this gold layer was approximately $30 \mathrm{~nm}$. Figure 2(a) shows the apex of the tip presented in Fig. 1(a), after deposition of the gold layer. The coating increases the tip curvative radius up to $85 \mathrm{~nm}$. The typical grain size of the layer is $80 \mathrm{~nm}$ at the tip apex and 50 to $80 \mathrm{~nm}$ along the lateral parts of the tip. An EDX spectrum (probe size of 3-4 $\mathrm{nm}$ ), carried out at the tip extremity, confirms gold presence at the apex of the platinum tips [Fig. 2(b)]. Platinum is also detected due to the large volume of material analyzed in EDX microanalysis (roughly $1 \mu \mathrm{m}^{3}$ ) and to the low thickness of the gold layer. Quantitative microanalyses (ZAF corrections) revealed a higher quantity of platinum than expected from a short glance at the spectrum. This fact is highlightened by the high-energy peaks. Note that the $\mathrm{Al}$ peak deals with the tip holder used in all SEM experiments.

To deposit gold dots and lines, we applied negative voltage pulses to the sample while controlling the tunneling current at the value of $500 \mathrm{pA}$. The pulse magnitude was varied between -4.0 (voltage threshold) and $-4.4 \mathrm{~V}$ and the pulse duration was fixed at the value of $50 \mu$ s. Figure 3 shows a STM image of three dotted lines deposited close to the voltage threshold. The dots are regularly spaced along the lines.

In all studies concerning the fabrication of nanostructures, the most critical point is the determination of the chemical composition of the deposits. We have estimated this composition by EDX analysis. However, according to the penetration depth of the electron in a SEM, it is not possible to analyze lines or dots as thin as those shown on Fig. 3. For this reason, we have deposited thicker dots by applying highamplitude voltage pulses $(-10 \mathrm{~V})$ to the sample [Fig. 4(a)]. Figure 4(b) shows the EDX spectrum of the dot, at a SEM probe diameter of 3-4 $\mathrm{nm}$. Only silicon and gold are detected, and no trace of platinum is observed.

The tip was examined after its use for lithography. Figure 5(a) shows a SEM image of the tip apex. The dispersion of grain size is narrower than before lithography and the grain size has slightly increased up to $100 \mathrm{~nm}$. The curvative radius seems to be improved: $50 \mathrm{~nm}$ instead of $85 \mathrm{~nm}$. Figure 5(b) shows an EDX spectrum of the platinum tip after lithography. The tip is now composed of gold and no trace of platinum is detected on the tip extremity. Note that this spectrum was acquired at a logarithmic scale, which explains why the signal-to-noise ratio seems to be higher in Fig. 5 than in Fig. 2.

Particular care was taken to analyze the tip extremity at a roughly constant incident angle regarding the EDX electronbeam probe. Consequently, the difference between the two EDX spectra of the tip before and after lithography cannot be attributed to a variation of electron path through the gold coating. Furthermore, the volume analyzed in EDX microanalysis is in the range of $1 \mu \mathrm{m}^{3}$. Figure 6 shows a scheme presenting the electron probe and the platinum tip extremity coated by the gold layer. The volume probed at the tip extremity is far larger than the tip apex curvature (110 $\mathrm{nm}$ ), and the x-ray fluorescence signal comes from areas at distances of about one order of magnitude higher than the tip apex curvature. This explains why the platinum peak is higher than the gold one in the spectrum taken before lithography experiments.

According to the preceding remarks dealing with the volume analyzed in EDX experiments, the fact that only gold is detected in spectra taken after lithography means that the tip extremity is now composed of pure gold and that a phenomenon of gold transfer occurs during the application of voltage pulses during lithography. To confirm this hypothesis, we have studied the tip transformation during the deposition process under application of a great number (100) of voltage

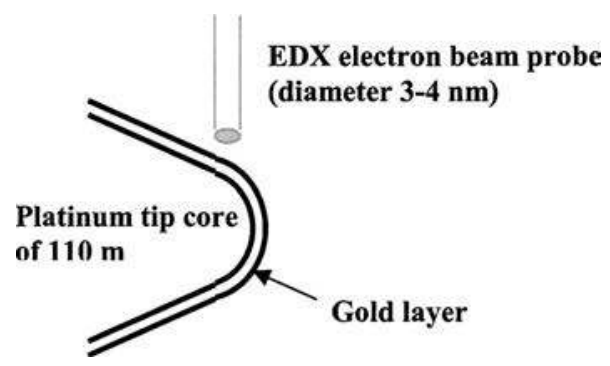

FIG. 6. Scheme presenting the incident electron probe for EDX microanalysis and the platinum tip extremity coated by the gold layer. 


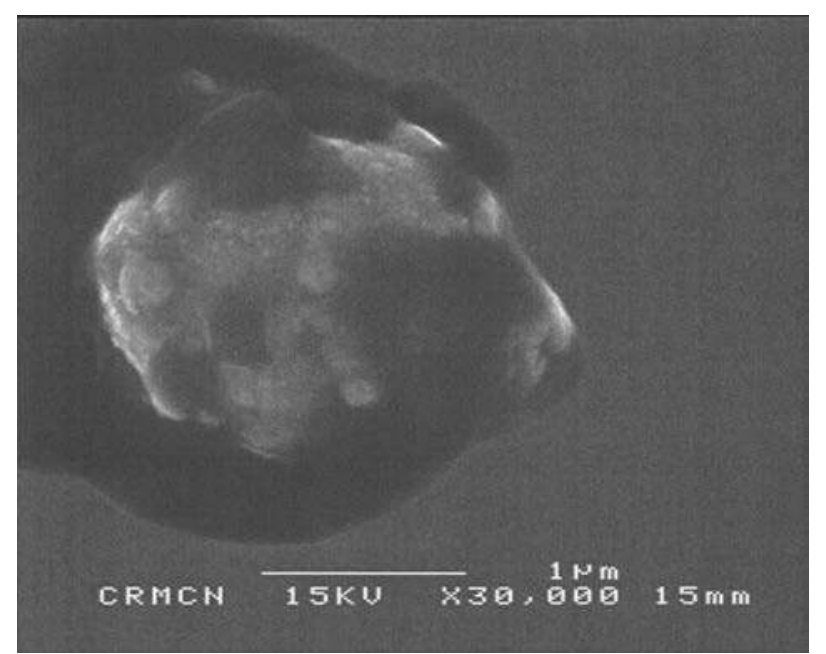

FIG. 7. SEM analysis of the morphology of the extremity of a platinum tip coated by a thin gold layer, observed just after application of a series of 100 voltage pulses of high amplitude $(-10 \mathrm{~V})$.

pulses of high amplitude $(-10 \mathrm{~V})$, which must enhance the atom diffusion. Figure 7 shows the tip apex after deposition in these extreme experimental conditions. We can clearly observe the formation of a high-volume gold ball at the tip extremity, and the EDX spectrum was completely identical to that shown in Fig. 5(b).

Two different mechanisms have been suggested to explain the atom transfer from the tip to the sample. The first one is tip evaporation under the high tip-sample electric field. ${ }^{1,16,17}$ However, such a mechanism can explain neither the kinetics data obtained, the STM tip behavior during the deposition process ${ }^{4}$ nor the modification of the tip apex composition (gold instead of gold-coated platinum). More recently, it was shown that a physical contact is established during voltage pulse application. ${ }^{3,4,22}$ The consequence is a drastic tipsample current increase of about 4 orders of magnitude, ${ }^{4}$ reaching the microamp range, instead of the typical value of $500 \mathrm{pA}$ during imaging. The high current density flowing through the tip-sample bridge induces the local melting of the tip-sample neck. Finally, during the sampling period following the moment of the pulse application, the feedback loop of the STM acts to remove the STM tip from the sample

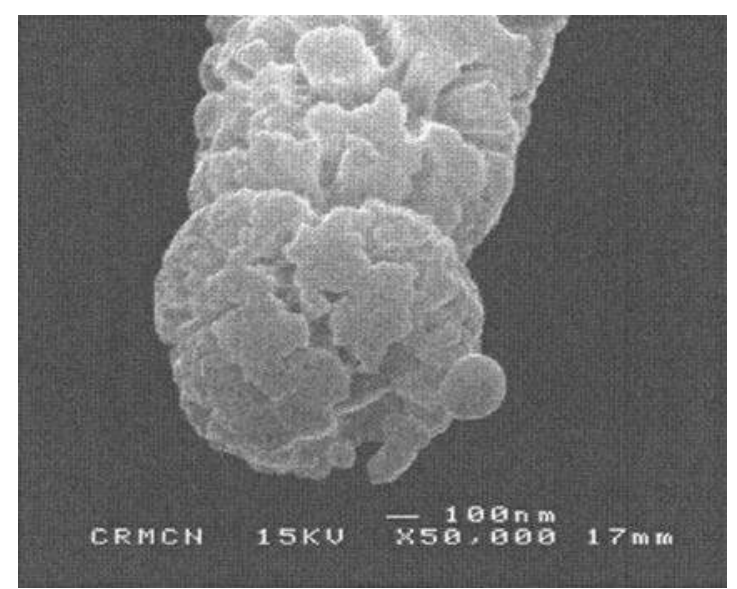

FIG. 8. SEM analysis of the morphology of the extremity of a platinum tip coated by a thin gold layer, observed just after application of a series of 10 voltage pulses of high amplitude $(-10 \mathrm{~V})$.

in order to again find the current setpoint of the regulation. The molten neck is broken during this tip motion and a droplet of liquid metal is left on the surface. Consequently, the process is likely to occur under a very high local temperature, which explains the deposit morphology with large grains of $300 \mathrm{~nm}$ diameter (Fig. 4). This deposition process in liquid phase can also explain why, although a physical tip-sample contact is established, the tip apex remains of high quality, which allows us to pattern regular dotted lines.

The tip-sample system can be considered as a metal insulator semiconductor structure and the actual voltage between tip and sample depends on the work function of the metal used for the tip and on the type and level of doping of the sample. ${ }^{4}$ The actual voltage at threshold between a $n$-type sample of doping level $4 \times 10^{13} \mathrm{~cm}^{-3}$ and the metallic tip is given in Table I in the case of gold, platinum, and tungsten tips. The cohesion energy of these metals is also indicated in this table. Although gold and platinum have very different cohesion energy, the voltage threshold is the same for platinum- and gold-coated platinum tips. Thus, the cohesion energy is not the pertinent criteria to explain the differences in voltage thresholds.

TABLE I. Actual tip-sample voltage threshold to observe the tip to sample atom transfer for different tips.

\begin{tabular}{lccccc}
\hline \hline & $\begin{array}{c}\text { Metal work } \\
\text { function } \\
(\mathrm{eV})\end{array}$ & $\begin{array}{c}\text { Voltage } \\
\text { threshold } \\
(\mathrm{V})\end{array}$ & $\begin{array}{c}\text { Actual tip-sample } \\
\text { voltage } \\
\text { at threshold } \\
(\mathrm{V})\end{array}$ & $\begin{array}{c}\text { Cohesion } \\
\text { energy } \\
\text { at } 0 \mathrm{~K}^{\mathrm{b}} \\
(\mathrm{eV})\end{array}$ & $\begin{array}{c}\text { Elasticity } \\
\text { modulus }^{\mathrm{a}} \\
(\mathrm{Gpa})\end{array}$ \\
\hline $\begin{array}{l}\text { Gold-coated platinum tip } \\
\text { on } n \text {-type Si } 4 \times 10^{13} \mathrm{~cm}^{-3}\end{array}$ & 5.1 & -4.0 & -3.16 & 3.81 & $\begin{array}{l}\text { Platinum } 168 \\
\text { Platinum tip } \\
\text { on } n \text {-type Si } 4 \times 10^{13} \mathrm{~cm}^{-3}\end{array}$ \\
$\begin{array}{l}\text { Tungsten tip } \\
\text { on } n \text {-type Si } 4 \times 10^{13} \mathrm{~cm}^{-3}\end{array}$ & 5.6 & -4.5 & -3.26 & 5.84 & 168 \\
\hline
\end{tabular}

${ }^{\mathrm{a}}$ See Ref. 23

${ }^{\mathrm{b}}$ See Ref. 24 
TABLE II. Coefficient of self-diffusion of platinum and tungsten on platinum and tungsten (see Ref. 25).

\begin{tabular}{|c|c|c|c|}
\hline & $D_{0}\left(\mathrm{~cm}^{2} \mathrm{~s}^{-1}\right)$ & $E(\mathrm{eV})$ & $\begin{array}{c}D\left(\mathrm{~cm}^{2} \mathrm{~s}^{-1}\right) \text { at room } \\
\text { temperature }\end{array}$ \\
\hline $\mathrm{Pt}$ & $10^{-3}$ & 0.4 & $2 \times 10^{-11}$ \\
\hline W & $10^{-3}$ & 0.78 & $8 \times 10^{-17}$ \\
\hline
\end{tabular}

The tip elongation can have two origins. First, considering the tip-sample system as a capacitor, the two terminals attract each other during pulse voltage application. Assuming a sphere-plane geometry, the value of the force at the extremity of the tip is about $2 \times 10^{-10} \mathrm{~N}$ when a pulse voltage of $1 \mathrm{~V}$ is applied to the sample. This value corresponds to a strength of $13 \mathrm{kPa}$ and to a relative elongation of $7.8 \times 10^{-8}$ (elasticity modulus of platinum: $168 \mathrm{GPa}$ ). Considering a tip length of $3 \mathrm{~mm}$, the tip elongation is of the order of $0.24 \mathrm{~nm}$ when a pulse of $1 \mathrm{~V}$ is applied to the sample. The voltage threshold of $4.2 \mathrm{~V}$, corresponding to an actual tip-sample voltage of $3.26 \mathrm{~V}$ (Table I), represents the voltage necessary to elongate the tip of $0.78 \mathrm{~nm}$, order of magnitude of the initial tipsample distance during the process of substrate imaging.

This elongation mode corresponds to a collective movement of atoms and in a rough approximation, the time necessary to elongate the tip corresponds to the time necessary to the sound to propagate along the tip, i.e., $1 \mu$ s (sound velocity in platinum of $3000 \mathrm{~m} \mathrm{~s}^{-1}$ ). This time constant is of the order of pulse voltage duration used in the lithography process.

In the hypothesis of a mechanical elongation, the voltage thresholds using different metallic tips must vary in the same ratio as the elasticity modulus of the metals. Experiments performed using tungsten and platinum tips seem to confirm the hypothesis of mechanical elongation due to the electrostatic force between tip and sample (Table I).

In the lithography process investigated, the coating of gold has a low elasticity modulus. Thus, the coating presence would not affect considerably the mechanical properties of the tip and the tip elongation might be the same with or without the gold layer. Thus the voltage threshold must remain constant after tip coating. This is clearly observed in the case of platinum- and gold-coated platinum tips but not for tungsten tips. Thus, this mechanism based on tip elastic elongation must not be definitively rejected, but cannot explain all the experimental results.

Another possible mechanism to explain the tip-sample contact establishment is based on the filling of the very narrow tip-sample gap with metal adatoms which diffuse along the lateral parts of the tip, towards the tip apex. This diffusion is enhanced by the high tip-sample electrical field. The coefficient of self-diffusion of adatoms on a surface is thermally activated and can be expressed as a function of temperature $T$ as follows:

$$
D=D_{0} \exp -E / K_{b} T
$$

where $K_{b}$ is the Boltzmann constant. Table II gives the values of the coefficient of self-diffusion of tungsten and platinum atoms on tungsten and platinum surfaces. ${ }^{25}$ Before contact establishment, the tip-sample current remains in the range of nanoamps (typical value of current setpoint in STM experiments) and consequently, the tip extremity remains at room temperature. In the case of platinum, the values of $D_{0}$ and $E$ are $10^{-3} \mathrm{~cm}^{2} \mathrm{~s}^{-1}$ and $0.46 \mathrm{eV}$, respectively at low temperature (in the range of 100 to $200 \mathrm{~K}$ ). The extrapolation of law (1), at room temperature, gives a coefficient of self-diffusion of $2 \times 10^{-11} \mathrm{~cm}^{2} \mathrm{~s}^{-1}$. During the voltage pulse of $50 \mu \mathrm{s}$, the diffusion length of gold atoms is $0.3 \mathrm{~nm}$. This distance is also of the order of the tip-sample distance in our experimental sample bias conditions. Consequently, the pulse voltage is long enough to allow gold atom diffusion towards the substrate surface, but the tip-sample gap filling cannot be explained by a diffusion controlled process due to the very low diffusion coefficient at room temperature. Furthermore, in the case of tungsten, the diffusion coefficient is even too low to allow atoms to reach the sample at room temperature leading to the tip-sample contact. Note that the high tip-sample electric field was not taken into account for the calculation of the diffusion coefficients.

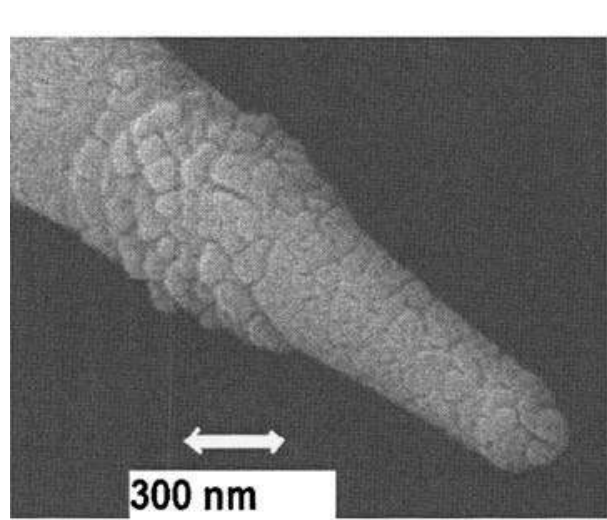

(a)

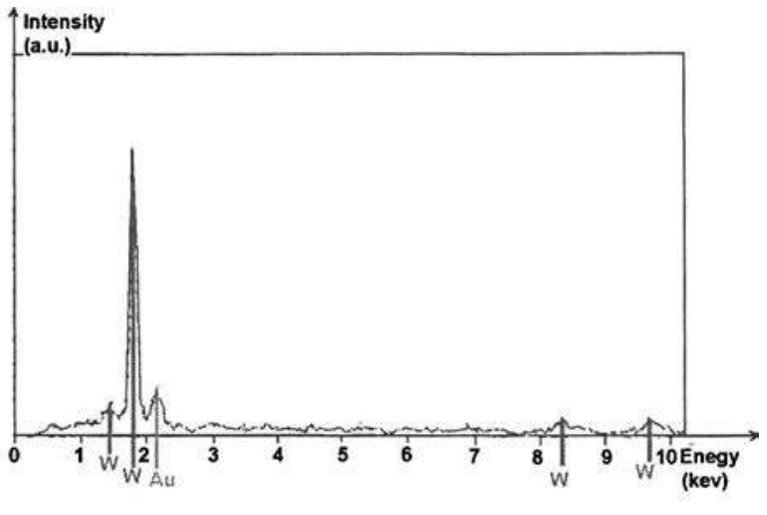

(b)

FIG. 9. Analysis of a gold-coated tungsten tip just before lithography. (a) Tip morphology studied by SEM. (b) Chemical analysis of the tip apex by EDX. 


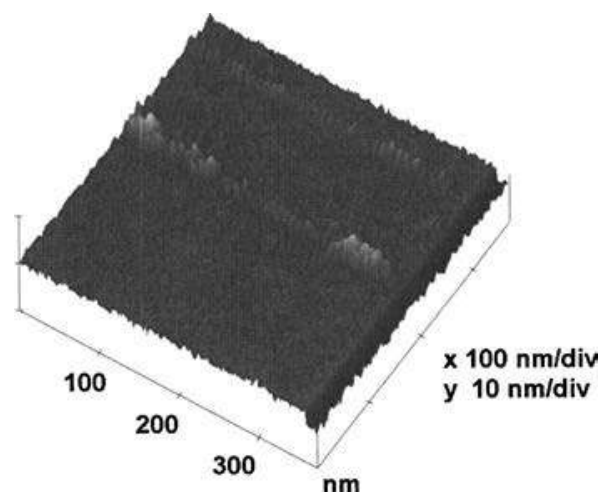

FIG. 10. Gold line deposited using a gold-coated tungsten line.

When high-voltage pulses $\left(V_{\text {litho }}=-10 \mathrm{~V}\right)$ are applied to the sample, the tip morphology changes (Fig. 8) and large spherical clusters of pure gold are formed at the tip extremity. The grain diameters are of the order of 200 to $300 \mathrm{~nm}$ and their formation can be explained only by a drastic increase of temperature at tip extremity during the atom transfer, due to the flow of a high current density through the tip apex.

Although it is difficult to reject one of the two mechanisms, the observation of the tip curvature decrease after lithography can be more easily understood if one assumes that the apex is continuously renewed by atom migration from the lateral parts of the tip. However, the tip-sample contact establishment is probably due to a mechanical deformation/elongation of the tip. As soon as the contact is established, the current density increases drastically through the gold bridge, which melts. At temperature of gold melting point $(1336 \mathrm{~K})$, the self-diffusion coefficient of gold is now $2.5 \times 10^{-3} \mathrm{~cm}^{2} \mathrm{~s}^{-1}\left[D_{0}=3 \times 10^{3} \mathrm{~cm}^{2} \mathrm{~s}^{-1}\right.$ and $E=1.74 \mathrm{eV}$ (see Ref. 25)], i.e., eight orders of magnitude higher than at room temperature, and consequently high temperature enhances the field-diffusion of gold atoms towards the tip apex, which explains for example the formation of very large gold balls at the tip extremity when we applied high-voltage pulses (Fig. 7).

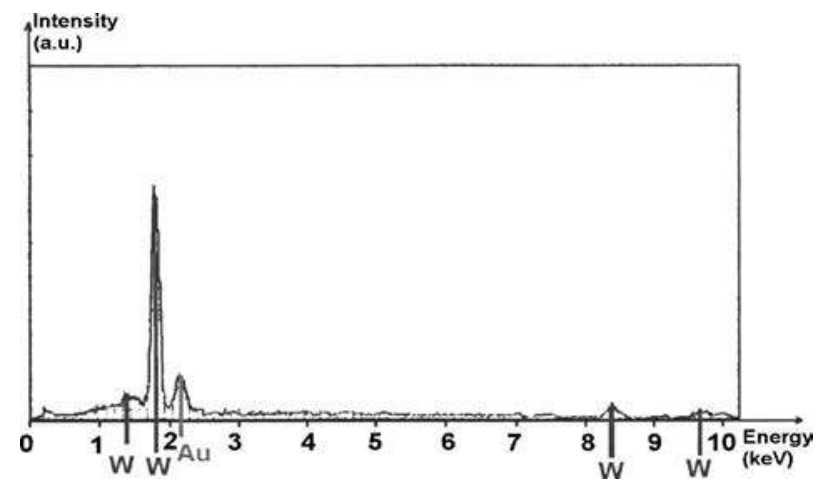

FIG. 11. EDX spectrum of a gold-coated tungsten tip after lithography experiments.

\section{B. Deposition from gold-coated tungsten tips}

Identical experiments have been carried out using tungsten tips instead of platinum wires. Figure 9(a) shows the morphology of a typical wire coated by a gold layer deposited in the same conditions as in the case of platinum tips. The tungsten tips are sharper and typical curvative radius of $50 \mathrm{~nm}$ are commonly obtained. The gold layer is discontinuous, and both tungsten and gold are detected on the EDX spectrum [Fig. 8(b)].

The presence of the gold coating decreases the process voltage threshold from $-7.2 \mathrm{~V}$ to $-4.2 \mathrm{~V}$, due to the change in cohesion energy and work function linked to the change of metal (gold instead of tungsten). However, it was not possible to draw continuous lines with such tips as shown in Fig. 10. Deposition is not well controlled and is stopped from time to time, while the tip scans the surface. Figure 11 shows the EDX spectrum of the tip just after lithography. Contrary to the case of platinum tip, the signature of tungsten is still strongly present on the spectrum even after lithography. This means that the deposition process was not sufficient to improve the tip coverage and that the extremity of a tungsten tip is less fed in gold atoms than in the case of platinum tips. This can be explained by the difference between the gold atom diffusion coefficient on tungsten and on platinum sur-

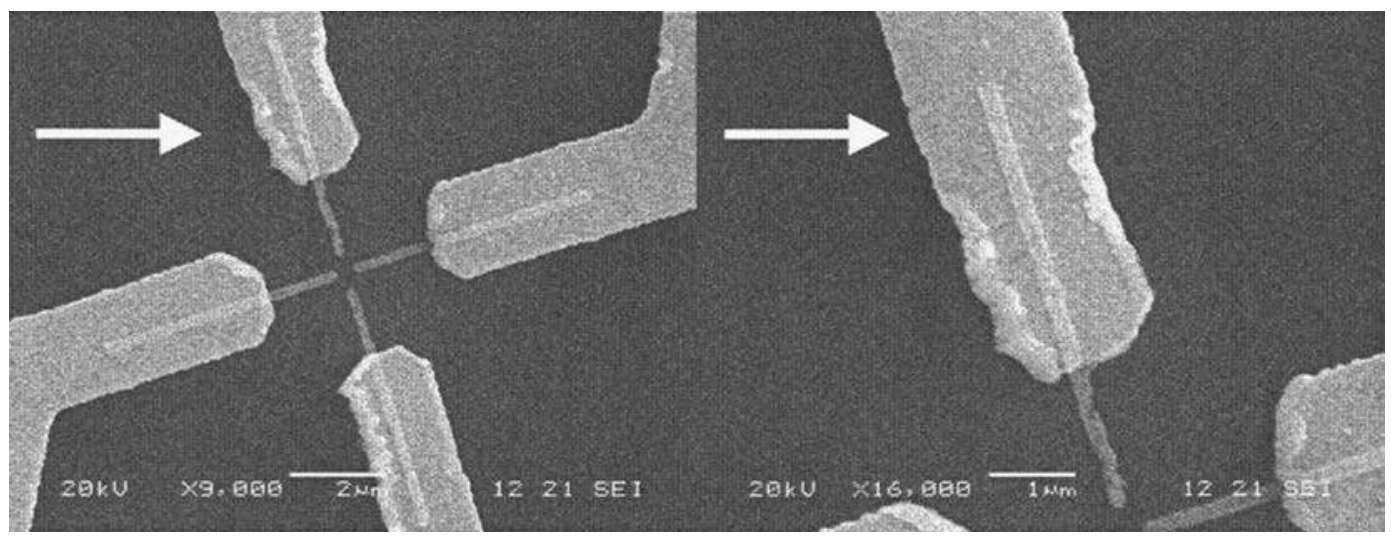

FIG. 12. Gold test pattern observation by SEM just after being imaged by STM. (a) General top view. The arrow indicates the direction of the STM tip scan. (b) Zoom on the extremity of a contact lead that was perpendicular to the direction of scan of the STM tip. 


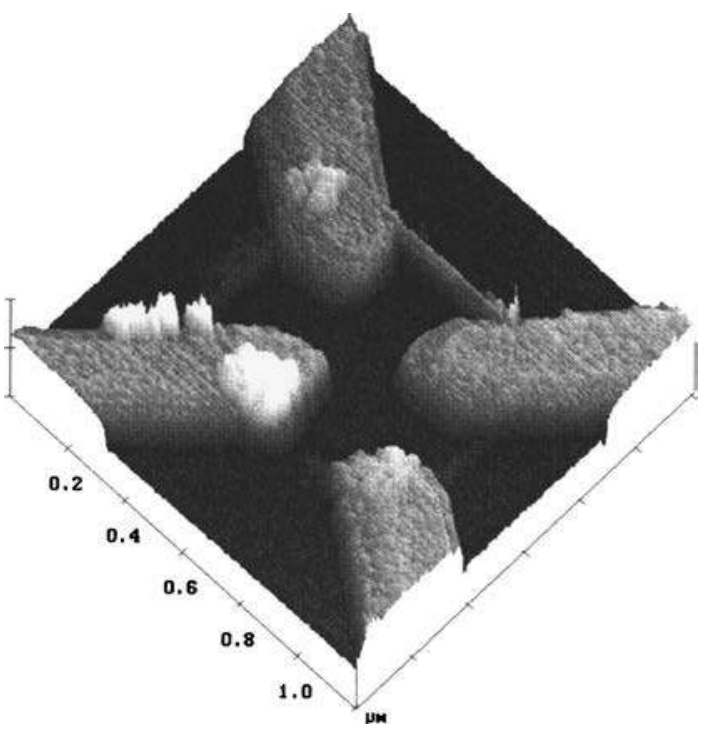

FIG. 13. Gold nanowire drawn between two gold leads.

faces. In fact the diffusion of metallic atoms on a surface of another metal is easier if the melting point of the two metals are of the same order of magnitude. The melting points of gold, platinum, and tungsten are, respectively, 1063, 1769, and $3410{ }^{\circ} \mathrm{C}$, and thus the diffusion of gold atoms on a platinum surface must be easier than on a tungsten surface.

\section{Direct bonding by STM field evaporation}

The final step was to try to carry out electrical measurement on the gold nanowires drawn by this direct lithography process. For that purpose, the lines have been drawn inside a test pattern previously fabricated by e-beam lithography. It consists of four gold contact leads converging to the center of the chip and linked to large pads, allowing line connection by conventional wire bonding. The distance between the extremities of the lead is about $500 \mathrm{~nm}$ and the thickness of the leads is $80 \mathrm{~nm}$. It was chosen to fabricate this pattern in gold to avoid its damage during the preliminary wet etching procedure in HF solution.

The sample was first imaged by STM to align the pattern regarding the STM lithography tool. This operation took roughly $20 \mathrm{~min}$ and required several tip scans over the pattern. Figures 12(a) and 12(b) show the pattern morphology just after imaging by STM with a direction of tip scan indicated by the arrow. This figure shows clearly that the pattern has been damaged by the STM tip; only the leads perpendicular to the tip scan are damaged. The tip apex has also been destroyed during imaging, and even if lines could be directly drawn inside the test pattern, the resolution reached was never better than $50 \mathrm{~nm}$ (Fig. 13). Consequently, the only way to carry out electrical measurements on gold nanowires is to draw the nanowires inside a test pattern embedded in the sample, to avoid high topographic contrast of the surface during the procedure of sample alignment regarding the STM.

\section{CONCLUSION}

Direct writing of gold nanofeatures can be achieved on silicon surfaces by field-induced deposition under a platinum STM tip coated with a thin gold layer. The tip to sample atom transfer occurs when voltage pulses of amplitude lower than a threshold of $-4 \mathrm{~V}$ are applied to the sample. The fabrication process of the tip is easy to control and nanodots of pure gold (as shown by EDX analyses performed on wider dots) of about 10 to $15 \mathrm{~nm}$ in diameter can be reproducibly created on the silicon surface at room temperature. The deposition process mechanism involves a step of formation of a tip-sample contact due to the tip mechanical elongation under the high tip-sample electric field. As soon as the contact is established, the current density increases about four orders of magnitude, which leads to the local drastic temperature increase at the tip extremity and then to the formation of a molten tip-sample bridge. Consequently, although the process occurs on a sample kept at room temperature, the gold dots are deposited by field-induced diffusion of gold atoms in liquid phase. The deposit morphology is thus highly influenced by the wetting properties of gold, regarding both sample nature and metal used for the tip. This explains why, in working with tungsten STM tips (lower wettability of tungsten than platinum regarding gold) coated by a gold layer of thickness equivalent to the case of platinum tips, the experiments were not reliable and it was not possible to draw continuous nanowires. This technique can be extended to the patterning of nanofeatures of other metals evaporated or sputtered on the STM tip. The condition to succeed in drawing continuous lines is the good wettability of the tip, regarding the metallic coating.

It was not possible to carry out electrical tests on these gold nanowires, since the STM tip damages the micronic test pattern previously drawn on the sample during the alignment procedure of the sample regarding the lithography tool. However, direct bonding of contact leads by this nanolithography technique should be possible, using embedded test patterns to avoid high topographic contrast on the surface observed by the STM.

${ }^{1}$ H. J. Mamin, P. H. Guethner, and D. Rugar, Phys. Rev. Lett. 65, 2418 (1990).

${ }^{2}$ G. S. Hsiao and R. M. Penner, Appl. Phys. Lett. 64, 1350 (1994).

${ }^{3}$ D. H. Huang, T. Nakayama, and M. Aono, Appl. Phys. Lett. 73, 3360 (1998).

${ }^{4}$ A. Houel, D. Tonneau, N. Bonnail, H. Dallaporta, and V. Safarov, J. Vac. Sci. Technol. B 20, 2337 (2002).

${ }^{5}$ G. S. Hsiao, R. M. Penner, and J. Kingsley, Appl. Phys. Lett. 64, 1350 (1994).

${ }^{6}$ D. Fujita, Q. D. Jiang, Z. C. Dong, H. Y. Sheng, and H. Nejoh, Nanotechnology 8, A10 (1997).

${ }^{7}$ J. A. Dagata, J. Schneir, H. H. Harary, C. J. Evans, M. T. Postek, and J. Bennett, Appl. Phys. Lett. 56, 2001 (1990).

${ }^{8}$ E. S. Snow, P. M. Campbell, and P. J. McMarr, Appl. Phys. Lett. 63, 749 (1993).

${ }^{9}$ P. M. Campbell, E. S. Snow, and P. J. McMarr, Appl. Phys. Lett. 66, 1388 (1995).

${ }^{10} \mathrm{Ph}$. Avouris, T. Hertel, and R. Martel, Appl. Phys. Lett. 71, 285 (1997).

${ }^{11}$ B. Legrand and D. Stievenard, Appl. Phys. Lett. 74, 4049 (1999).

${ }^{12}$ N. Clément, D. Tonneau, H. Dallaporta, V. Bouchiat, D. Fraboulet, D. Mariole, J. Gautier, and V. Safarov, Physica E (Amsterdam) 13, 999 (2002). 
${ }^{13}$ N. Clément, A. Francinelli, D. Tonneau, H. Dallaporta, F. Jandard, D. Fraboulet, J. Gautier, and V. Safarov, Appl. Phys. Lett. 82, 1727 (2003).

${ }^{14}$ N. Clément, D. Tonneau, B. Gely, H. Dallaporta, V. Safarov, and J. Gautier, J. Vac. Sci. Technol. B 21, 2348 (2003).

${ }^{15}$ F. Marchi, V. Bouchiat, H. Dallaporta, V. Safarov, and D. Tonneau, J. Vac. Sci. Technol. B 16, 2952 (1998).

${ }^{16}$ C. S. Chang, W. B. Su, and T. T. Tsong, Phys. Rev. Lett. 72, 574 (1994).

${ }^{17}$ K. Bessho and S. Hashimoto, Appl. Phys. Lett. 65, 17 (1994).

${ }^{18}$ L. Libioulle, Y. Houbion, and J. M. Gilles, Rev. Sci. Instrum. 66, 97 (1995).

${ }^{19}$ P. D. Szkutnik, A. Piednoir, A. Ronda, F. Marchi, D. Tonneau, H. Dallaporta, and M. Hanbücken, Appl. Surf. Sci. 164, 169 (2000).
${ }^{20}$ D. Fujita, Q. D. Jiang, and H. Nejoh, J. Vac. Sci. Technol. B 14, 3413 (1996).

${ }^{21}$ Y. J. Chabal, G. S. Higashi, K. Raghavachari, and V. A. Burrows, J. Vac. Sci. Technol. A 7, 2104 (1989).

${ }^{22}$ M. R. Sorensen, K. W. Jacoben, and H. Jonsson, Phys. Rev. Lett. 77, 5067 (1996).

${ }^{23}$ CRC Handbook of Chemistry and Physics, 75 th ed., edited by D. R. Lide (CRC Press, Boca Raton, FL, 1995).

${ }^{24}$ C. Kittel, Introduction to Solid States Physics, 7th ed. (Wiley, New York, 1996).

${ }^{25}$ E. G. Bauer and C. E. Allen, Prog. Surf. Sci. 49, 265 (1995). 